\title{
Biometrics of the Cervical Spinal Canal and Cord by Computer Tomography in Togo
}

\author{
Abdoulatif Amadou ${ }^{1 *}$, Lantam Sonhaye ${ }^{1}$, Kossivi Apetse ${ }^{2}$, Komlan Amoussou ${ }^{1}$, \\ Mazamaesso Tchaou' ${ }^{3}$ Bidamin N'timon', Kahabilou Atsa Agbangba1, \\ Gani Watara1, Komlavi Adjenou' ${ }^{1}$
}

${ }^{1}$ Department of Radiology, Campus University Teaching Hospital of Lomé, Lomé, Togo

${ }^{2}$ Department of Neurology, Campus University Teaching Hospital of Lomé, Lomé, Togo

${ }^{3}$ Department of Radiology, Sylvanus Olympio University Teaching Hospital of Lomé, Lomé, Togo

${ }^{4}$ Department of Radiology, University Teaching Hospital of Kara, Kara, Togo

Email: ^amadoulatif@yahoo.fr

How to cite this paper: Amadou, A., Sonhaye, L., Apetse, K., Amoussou, K., Tchaou, M., N'timon, B., Agbangba, K.A., Watara, G. and Adjenou, K. (2017) Biometrics of the Cervical Spinal Canal and Cord by Computer Tomography in Togo. Open Journal of Radiology, 7, 45-53. https://doi.org/10.4236/ojrad.2017.71005

Received: February 14, 2017

Accepted: March 21, 2017

Published: March 24, 2017

Copyright (c) 2017 by authors and Scientific Research Publishing Inc. This work is licensed under the Creative Commons Attribution International License (CC BY 4.0).

http://creativecommons.org/licenses/by/4.0/ (c) (i) Open Access

\begin{abstract}
Studies on the canal dimensions of the cervical spinal are rare in Africa. The aim of this study is to provide normal values of the cervical spinal canal and spinal cord dimensions of adult people in Togo. It was about a twelve-year prospective study conducted in the main Hospitals of Campus Teaching Hospital. This study involved people of more than 18 years who neither presented any clinical sign nor rachis defect. The distances measured were antero-posterior 1 (APD1) and inter-pedicular (IPD) of the cervical spinal canal, the antero-posterior 2 (APD2) and the transverse (TD) diameters of the cervical spinal cord, followed with APD2/APD1 (R1) and TD/IPD (R2) research reports. The mean age was $38+/-9.34$ years old. The average of APD1 of the cervical spinal canal stood at $15.41 \pm 0.55 \mathrm{~mm}$, with a minimum of $10.48 \pm$ $0.57 \mathrm{~mm}$ and a maximum of $25.00 \pm 2.60 \mathrm{~mm}$. The IPD average stood at 23.27 $\pm 1.67 \mathrm{~mm}$ with a minimal average of $13.68 \pm 1.46 \mathrm{~mm}$ and a maximal average of $33.68 \pm 1.46 \mathrm{~mm}$. The average of DAP2 was $11.66 \pm 0.66 \mathrm{~mm}$, with a minimum of $10.7 \pm 0.66 \mathrm{~mm}$ and a maximum of $12.77 \pm 0.66 \mathrm{~mm}$. The DT average stood at $15.55 \pm 1.54 \mathrm{~mm}$, with a minimal average of $14.03 \pm 2.43 \mathrm{~mm}$ and a maximal average of $17.63 \pm 1.82 \mathrm{~mm}$. The ratio $\mathrm{R} 1$ (APD2/APD1) average was $0.80 \pm 0.04$, with a minimum of $0.76 \pm 0.06$ and a maximum of $0.85 \pm$ 0.07 . The ratio $\mathrm{R} 2(\mathrm{TD} / \mathrm{IPD})$ average stood at $0.69 \pm 0.14$, with a minimum of $0.5 \pm 0.12$ and a maximum of $0.84 \pm 0.08$. The cervical spinal canal and the cervical spinal cord diameters in Togo are not significantly different from those described above.
\end{abstract}

\section{Keywords}

Cervical Spinal Canal, Cervical Spinal Cord, Biometrics, CT Scan-Togo 


\section{Introduction}

Spinal stenosis is a major predisposing factor for cervical myelopathy and spinal cord injury [1] [2]. The spinal canal can be tightened congenitally or take the tight form by arthritic injuries resulting in its strong biomechanical implication [3]. The information with regard to the accurate dimensions of the spinal canal is important to suggest the diagnosis for the constitutional tight canal and the spinal surgery. Thus the scanning plays a crucial role for measuring the lumbar canal and the canal tightness diagnosis. The Computer Tomography (CT Scan) and the Magnetic Resonance Imaging (MRI) are the most efficient and the most used imagery tools to diagnose the tightness of the cervical canal. It is seldom to encounter studies that deal with the normal dimensions of the cervical spinal canal and cervical spinal cord in Black Africa. Hence, few studies have assessed the dimensions of the spinal cord, either in terms of MRI or CT Scan. So, we undertook this work to determine in, by $\mathrm{CT}$ scan, the biometrics of the cervical spinal canal and cervical spinal cord of adult people in Togo, and then assess the ratio between the cervical spinal cord and cervical spinal canal.

\section{Material and Method}

It was prospective study carried out over a twelve-month (12) period at the university hospital center of the campus. It concerns CT Scans of adults people of more than 18 years, who did not present any clinical sign of neck pain or cervicobrachial neuralgia. We excluded from our study the cervical spinal which presented malformation, degenerative, infectious, rheumatic, traumatic lesions or spinal surgery backgrounds.

The studies have been carried out on General Electric's CT Scan. The volume acquisition has been realized on the cervical spinal. The stocked images have been processed on the image processing console with the measurement tools that facilitate the enlargement and rotation.

The measurement of the dimensions of the cervical spinal canal and spinal cord was realized on pedicular axial CT Scan cuts.

The distances measured were the antero-posterior (APD1) and inter-pedicular (IPD) diameters of the cervical spinal canal, as well as the antero-posterior (APD2) and transverse diameters (TD) of the spinal cord. Then we assessed APD2/APD1 (R1) and TD/IPD (R2) ratio.

APD1 has been measured between the posterior edge of the vertebral body and the fore junction of the blades (Figure 1).

IPD represents the longest distance between two pedicles (Figure 1).

APD2 has been measured between the anterior and the posterior edges of the spinal cord (Figure 2), at the same level as the APD1, in order to assess their ratio (R1).

TD has been measured between the right and the left edges of the spinal cord (Figure 2), at the same level as the IPD, in order to assess their report (R2).

The data have been processed and analyzed with Epi info 7 and Microsoft Excel software. 


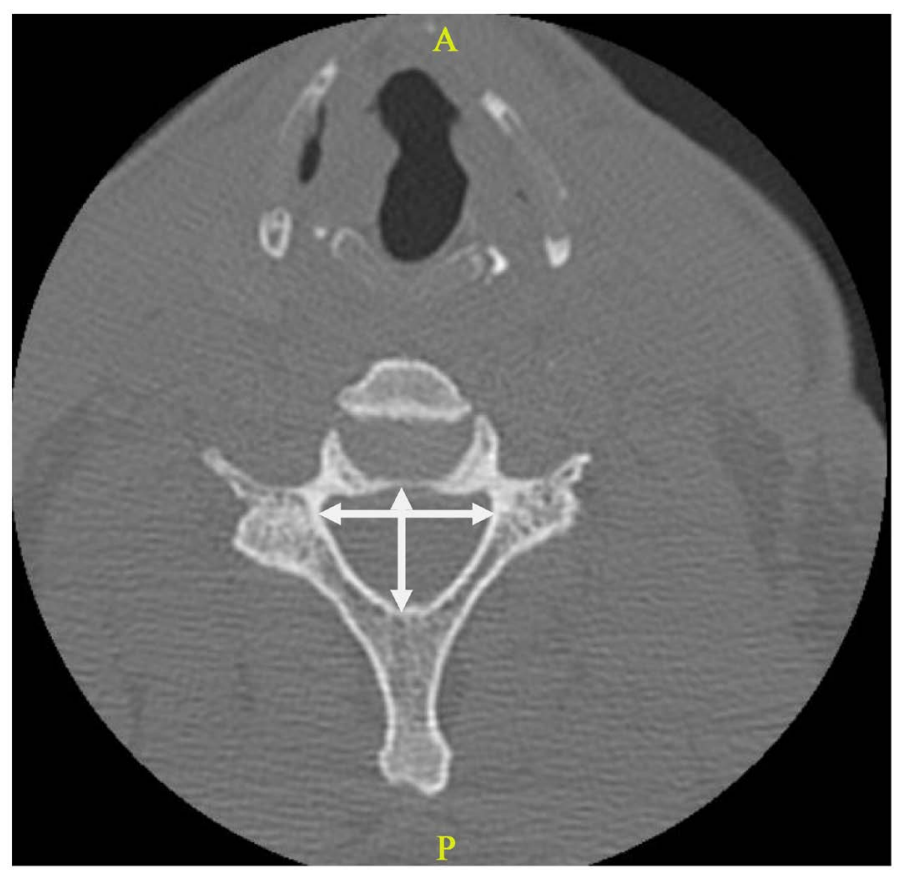

Figure 1. Measurements of anteroposterior diameter (APD1) and interpedicular diameter (IPD) of cervical spinal canal.

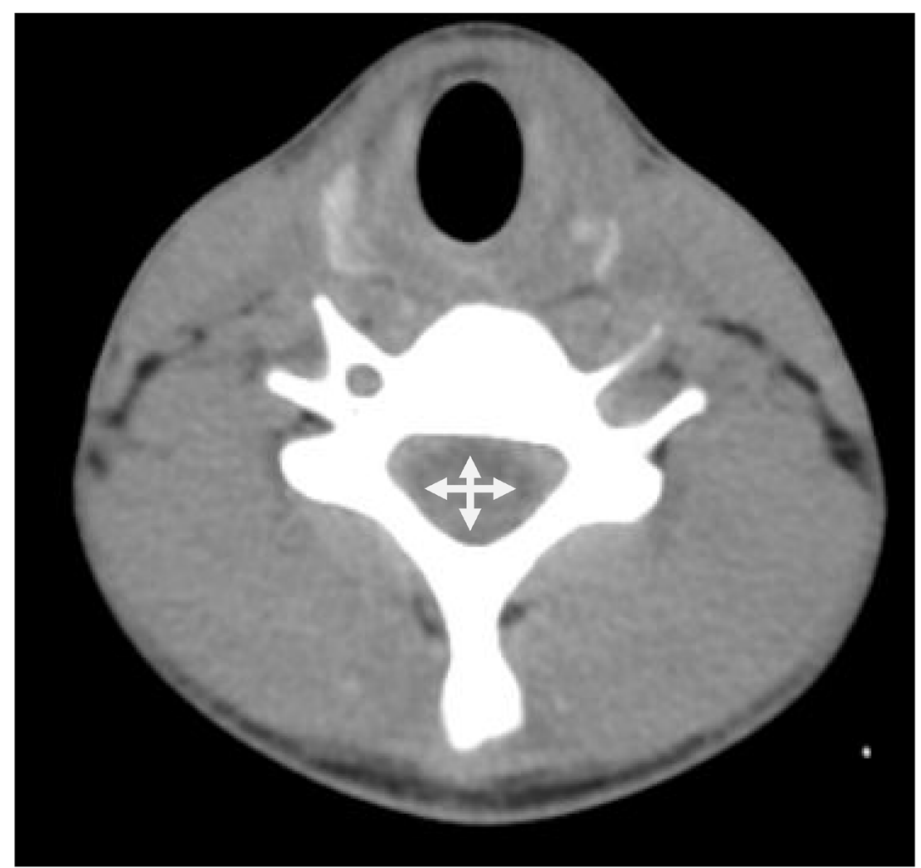

Figure 2. Measurements of anteroposterior diameter (APD2) and transverse diameter (TD) of cervical spinal cord.

\section{Results}

Our study involved $350 \mathrm{CT}$ Scans of the cervical spinal. The mean age stood at $35 \pm 10.55$ years old. Both genders were involved, with 217 men (62\%) and 133 women (38\%).

The average of the APD1 stood at $14 \pm 2.1 \mathrm{~mm}$, with a minimal average of 
$12.7 \pm 1.5 \mathrm{~mm}$ and a maximal average of $18.3 \pm 1.9 \mathrm{~mm}$. The highest average was at $\mathrm{C} 1$ and the lowest at $\mathrm{C} 3, \mathrm{C} 4$ and C5 (Table 1).

The IPD average was $24 \pm 1.3 \mathrm{~mm}$, with a minimal average of $22.2 \pm 1.8 \mathrm{~mm}$, and a maximal average of $26 \pm 1.9 \mathrm{~mm}$. We found the highest average at C1 and the lowest at $\mathrm{C} 2$ and $\mathrm{C} 3$ (Table 2).

The APD2 average was $11.66 \pm 0.66 \mathrm{~mm}$, with a minimal average of $9.1 \pm 0.67$ $\mathrm{mm}$ and a maximal average of $10.5 \pm 1.5 \mathrm{~mm}$. The highest average was found at $\mathrm{C} 1$ then at C2. From C3 to C7, the averages were slightly lower, but substantially equal (Table 1).

Table 1. Measures of Antero-Posterior Diameters (APD1) of the cervical spinal canal and the cervical spinal cord (APD2), and the ratio of the APD1 on the dural sac APD.

\begin{tabular}{ccccccc}
\hline & \multicolumn{2}{c}{ SPINAL CANAL (APD1) } & \multicolumn{2}{c}{ SPINAL CORD (APD2) } & \multicolumn{2}{c}{ RATIO 1 (R1) } \\
\cline { 2 - 7 } & Min - Max & Mean & Min - Max & Mean & Min - Max & Mean \\
\hline C1 & $15.4-21$ & $18.3 \pm 1.9$ & $8.5-14$ & $10.5 \pm 1.5$ & $0.43-0.68$ & $0.54 \pm 0.09$ \\
C2 & $12.3-17.7$ & $15.5 \pm 2.2$ & $7.4-11.1$ & $9.33 \pm 1.3$ & $0.49-0.67$ & $0.58 \pm 0.07$ \\
C3 & $10.3-14.2$ & $12.7 \pm 1.4$ & $7-10.5$ & $8.6 \pm 1.0$ & $0.43-0.67$ & $0.55 \pm 0.07$ \\
C4 & $10-15$ & $12.7 \pm 1.5$ & $7-10$ & $8.6 \pm 0.9$ & $0.44-0.65$ & $0.54 \pm 0.05$ \\
C5 & $11.1-14.6$ & $12.6 \pm 1.3$ & $7.7-10$ & $8.9 \pm 0.6$ & $0.46-0.64$ & $0.54 \pm 0.05$ \\
C6 & $11.6-14.4$ & $13.3 \pm 1.3$ & $7.2-11.6$ & $9 \pm 1.3$ & $0.48-0.64$ & $0.56 \pm 0.06$ \\
C7 & $11.2-14.7$ & $13.1 \pm 1.2$ & $8-10$ & $8.7 \pm 0.6$ & $0.44-0.77$ & $0.55 \pm 0.1$ \\
General & $12.7 \pm 1.5$ & & $9.1 \pm 0.67$ & & $0.54 \pm 0.05$ & \\
average & $18.3 \pm 1.9$ & $14 \pm 2.1$ & - & $11.66 \pm 0.66$ & - & $0.55 \pm 0.01$ \\
\hline
\end{tabular}

$\mathrm{P}$ values are higher than 0.05 : absence of statistically significantly difference of diameters and the ratio between the male and female sex.

Table 2. Measures of the Inter-Pediculaire Diameter (IPD) of the cervical spinal canal and the Transverse Diameter (TD) of the cervical spinal cord, and the ratio of the IPD on the TD.

\begin{tabular}{ccccccc}
\hline & \multicolumn{2}{c}{ SPINAL CANAL (IPD) } & \multicolumn{2}{c}{ SPINAL CORD (TD) } & \multicolumn{2}{c}{ RATIO 2 (R2) } \\
\cline { 2 - 7 } & Min - Max & Mean & Min - Max & Mean & Min - Max & Mean \\
\hline C1 & $22-28.6$ & $26 \pm 1.9$ & $11-17.7$ & $14.63 \pm 2.5$ & $0.51-0.7$ & $0.57 \pm 0.05$ \\
C2 & $20-26.4$ & $22.2 \pm 1.8$ & $10.4-15$ & $12.8 \pm 1.5$ & $0.55-0.66$ & $0.6 \pm 0.04$ \\
C3 & $20.3-24.6$ & $22.5 \pm 1.2$ & $10.4-13.6$ & $12.3 \pm 1.3$ & $0.6-0.78$ & $0.67 \pm 0.05$ \\
C4 & $22.4-26.4$ & $24 . \pm 1.2$ & $10-15.7$ & $13.1 \pm 1.5$ & $0.6-0.79$ & $0.68 \pm 0.05$ \\
C5 & $22.3-27.4$ & $24.5 \pm 1.8$ & $7.7-10$ & $9 \pm 0.6$ & $0.61-0.8$ & $0.7 \pm 0.06$ \\
C6 & $22-28.4$ & $24.5 \pm 1.9$ & $11.5-16.5$ & $13.7 \pm 1.5$ & $0.6-0.75$ & $0.67 \pm 0.05$ \\
C7 & $22-25.3$ & $23.6 \pm 1.3$ & $10.3-17.7$ & $13 \pm 2.4$ & $0.57-0.9$ & $0.66 \pm 0.09$ \\
& $22.2 \pm 1.8$ & & $9 \pm 0.6$ & & $0.57 \pm 0.05$ & \\
General & - & $24 \pm 1.3$ & - & $12.64 \pm 1.77$ & - & $0.65 \pm 0.04$ \\
average & $26 \pm 1.9$ & & $14.63 \pm 2.5$ & & $0.7 \pm 0.06$ & \\
\hline
\end{tabular}

$\mathrm{P}$ values are higher than 0.05 : absence of statistically significantly difference of diameters and the ratio between the male and female sex. 
The TD average stood at $12.64 \pm 1.77 \mathrm{~mm}$. The Minimal TD average was $9 \pm$ $0.6 \mathrm{~mm}$ and the maximal average was $14.63 \pm 2.5 \mathrm{~mm}$. The highest average was at $\mathrm{C} 1$ and the lowest at C5 (Table 2).

The average of $\mathrm{R} 1$ was $0.55 \pm 0.01$, with a minimal average at C4 and C5 (0.54 $\pm 0.05 \mathrm{~mm})$ and maximal average at C2 $(0.58 \pm 0.07)$. All R1 were lower than 0.8 at all levels (Table 1).

The R2 average R2 stood at $0.65 \pm 0.04$, with a minimal average at C1 $0.57 \pm$ $0.05 \mathrm{~mm})$ which progressively increased to C5 $(0.7 \pm 0.06 \mathrm{~mm})$ and then decreases to C7 $(0.65 \pm 0.04 \mathrm{~mm})$. The R2 were lower than 0.9 at all levels (Table 2).

While comparing the measurements of the cervical spinal canal (APD1 and IPD) and the spinal cord (APD2 and TD), as well as R1 and R2 between the two genders, we found that there is no significant difference (Table 3 ).

\section{Discussion}

Knowing the normal values of the spinal canal is important, because it enables to detect central canal stenosis by reduction of the canal caliber [4].

The antero-posterior diameter of the cervical spinal canal (APD1) is important in traumatic, degenerative and inflammatory situations, and a small diameter of APD1 is associated to the increase of lesions occurrence [5]. Generally, it is admitted that a cervical canal stenosis exists when the APD1 of the cervical canal is under the threshold of $12 \mathrm{~mm}$ [5] [6]. The global average of the APD1 cervical spinal canal in our study stood at $14 \pm 2.1 \mathrm{~mm}$, with a larger APD1 at C1 and the lowest at C3, C4 and C5. We noticed a decrease of APD1 from C1 to C5. Singh et al. [7], as well as Gupta et al. [8] in India found an average higher (17.05 \pm $1.61 \mathrm{~mm}$ ) than ours. The average of our study is close to that of Lee et al. [9] in Korea, to Taitz [10] in South Africa and Gepstein [11] in Israel. Few studies [4] [10] found the smallest APD1 at C3. Some studies [7] [9] [12] found a smallest

Table 3. Comparison of the APD1 and the IPD of the cervical spinal canal, the APD2 and the TD of the cervical spinal cord, the ratio R1 and the ratio R2 between male and female patients (division of $\mathrm{P}$ values).

\begin{tabular}{ccccccc}
\hline & \multicolumn{2}{c}{ SPINAL CANAL } & \multicolumn{2}{c}{ SPINAL CORD } & \multicolumn{2}{c}{ RATIOS } \\
\cline { 2 - 7 } & APD1 & IPD & APD2 & TD & R1 & R2 \\
\hline C1 & 0.93 & 0.99 & 0.96 & 0.96 & 0.94 & 0.96 \\
C2 & 0.97 & 0.99 & 0.90 & 0.94 & 0.90 & 0.94 \\
C3 & 0.99 & 0.98 & 0.90 & 0.91 & 0.94 & 0.95 \\
C4 & 0.96 & 0.99 & 0.92 & 0.94 & 0.95 & 0.95 \\
C5 & 0.95 & 0.98 & 0.98 & 0.95 & 0.92 & 0.96 \\
C6 & 0.95 & 0.99 & 0.95 & 0.93 & 0.94 & 0.97 \\
C7 & 0.94 & 0.96 & 0.96 & 0.94 & 0.96 & 0.95 \\
\hline
\end{tabular}

$P$ values are higher than 0.05 : absence of statistically significantly difference of diameters and the ratio between the male and female sex. 
APD1 at C4. For most studies [7] [8] [10] [11] [13], the smallest APD1 would stand at $\mathrm{C} 5$. It necessary to consider that regardless of the type of population, the smallest APD1 would stand generally in $\mathrm{C} 3, \mathrm{C} 4$ or $\mathrm{C} 5$ as we mention it in our study. Singh et al. [7] found a decrease of the APD1 from C1 to C5. UlbriCH [14] noted a lowering from $\mathrm{C} 1$ to $\mathrm{C} 6$. Other studies [13] [15] noticed a fall from $\mathrm{C} 1$ to $\mathrm{C} 4$ with an increase to $\mathrm{C} 5$ and a decrease to C6. Our study as well as Singh et al. [7] has not found any statistical significant difference between the APD1 of the cervical spinal canal of men and those of women. However, Evangepolos et al. [13] noticed a significant difference between the genders at C1. The comparison of the APD1 of our study with those of Singh et al. [7] on the one hand and with those of Evangepolos et al. [13] on the other hand, revealed that the differences are not statistically important. As for Taitz [10], the APD1 would be larger with White people than Black people, without any important difference. It is thus considered that the cervical spinal canal biometrics would not be in relation with the phenotype. Measurements from Asians, Europeans and Africans would be the same. According to the study of Chazono et al. [16], a possible ethnical difference of the APD1 would exist, with a larger APD1 with Europeans and Americans than with Asians.

With regard to the interpedicular diameter of cervical spinal canal (IPD), our study found out a global average of $24 \pm 1.3 \mathrm{~mm}$ with a variation from $22.2 \pm 1.8$ $\mathrm{mm}$ to $26 \pm 1.9 \mathrm{~mm}$. We observed a higher average at $\mathrm{C} 1$ and lower average at C2 and C3. The averages of our study are comparable to that of Chazono et al. [16], who found out averages varying from $22.6 \mathrm{~mm}$ à $27.5 \mathrm{~mm}$, with a minimal average at C3 for Asian people $(22.6 \mathrm{~mm})$ and a maximal average in C5 for European and American people $(27.5 \mathrm{~mm})$. As for Chazono et al. [16], many studies found out the lowest IPD at C3 and the highest at C5. Like our study, Chazono et al. [16], have not found any significant statistical difference of IPD between ethnic groups.

Few studies concerning the measurement of the cervical spinal cord exist [14]. Studies [17] revealed that the average of antero-posterior diameter of the cervical spinal cord (APD2) varies between $5 \mathrm{~mm}$ and $6 \mathrm{~mm}$. Our study found out an average of APD2 higher than $11.66 \mathrm{~mm} \pm 0.66$ with a variation from $9.1 \mathrm{~mm} \pm$ $0.67 \mathrm{à} 10.5 \mathrm{~mm} \pm 1.5$. Yet, the diameters measurement of the cervical spinal cord only would not enable to determine a cervical spinal cord compression. But when the measurement of the cervical spinal cord is coupled with that of the cervical spinal canal, it is possible to calculate the gap or to establish the relationship between the two. Tierney et al. [2], in their study, measure the gap between the spinal cord and the spinal canal by calculating the difference between the two. Our study considered the relationship between the cord and the canal, with a global average ratio of $0.55 \pm 0.01$, minimal at C4 and C5 $(0.54 \pm 0.05$ $\mathrm{mm})$ and maximal at $\mathrm{C} 2(0.58 \pm 0.07)$ in the antero-posterior plan. In the transverse plan, the global average ratio was $0.65 \pm 0.04$, with a minimal average at $\mathrm{C} 1$ $(0.57 \pm 0.05 \mathrm{~mm})$ which was increasing progressively until C5 $(0.7 \pm 0.06 \mathrm{~mm})$; then it decreases to reach $\mathrm{C} 7(0.65 \pm 0.04 \mathrm{~mm})$. There is no study concerning the 
relationship between the cord and the medullar canal regardless of in the antero-posterior plan or in the transverse plan. It is acknowledged that the spinal cord compression is due to an inadequacy between the cord and the medullar canal [18]. The gap around the spinal cord would diminish at the level of the cervical low segment [2], increasing the risk of medullar compression at this level [19] [20]. In our study, the smallest antero-posterior ratio stands in C4 and $\mathrm{C} 5$, and the largest ratio stands in $\mathrm{C} 2$. With regard to transverse plan report, our study found out an increase of the ratio from $\mathrm{C} 1$ to $\mathrm{C} 5$, then a decrease from $\mathrm{C} 5$ to C7. The assessment of the gap around the cord would be more contributing than the diameters of the canal and the spinal cord and the medullar canal in the determination of the spinal cord compression [21].

\section{Conclusion}

CT scan can provide accurate cervical spinal canal and spinal cord measurements that could serve as a useful guide in the determination of the cervical canal stenosis. The dimensions of the cervical spinal canal and spinal cord in healthy individuals are dependent on spinal level. The consideration of these normal values should help radiologists and clinicians to interpret CT scan.

\section{Conflict of Interests}

The authors declare that there is no conflict of interest regarding the publication of this paper.

\section{References}

[1] Hukuda, S. and Kojima, Y. (2002) Sex Discrepancy in the Canal/Body Ratio of the Cervical Spine Implicating the Prevalence of Cervical of Cervical Myelopathy in Men. Spine, 27, 250-253. https://doi.org/10.1097/00007632-200202010-00009

[2] Tierney, R.T., Maldjian, C., Mattacola, C.G., Straub, S.J. and Sitler, M.R. (2002) Cervical Spine Stenosis Measures in Normal Subjects. Journal of Athletic Training, 37, 190-193.

[3] Freedman, B.A., Hoffler, C.E., Cameron, B.M., Rhee, J.M., Bawa, M., Malone, D.G., Bent, M. and Yoon, T.S. (2015) A Comparison of Computed Tomography Measures for Diagnosing Cervical Spinal Stenosis Associated with Myelopathy: A Case-Control Study. Asian Spine Journal, 9, 22-29. https://doi.org/10.4184/asj.2015.9.1.22

[4] Moo, S.K., Jeong, Y.P., Dong, K.C., Kyung, H.K., Sung, U.K., Keun, S.K. and Yong, E.C. (2012) A PET/CT-Based Morphometric Study of Spinal Canal in Korean Young Adults: Anteroposterior Diameter from Cervical Vertebra to Sacrum. Ko rean Journal of Spine, 9, 165-169.

[5] Lee, M.J., Cassinelli, E.H. and Riew, K.D. (2007) Prevalence of Cervical Spine Stenosis. Anatomic Study in Cadavers. The Journal of Bone and Joint Surgery, 89, 376-380.

[6] Lee, M.J., Garcia, R., Cassinelli, E.H., Furey, C. and Riew, K.D. (2008) Tandem Stenosis: Acadaveric Study in Osseous Morphology. The Spine Journal, 8, 1003- 1006. https://doi.org/10.1016/j.spinee.2007.12.005

[7] Singh, S. and Balakrishnan, M. (2013) Morphometric Study of Cervical Spine Ver- 
tebrae in Eastern Region Nepalese Population. Morphometric Study of Cervical Spine Vertebrae. Health Renaissance, 11, 224-228.

[8] Gupta, S.K., Roy, R.C. and Srivastava, A. (1982) Sagittal Diameter of the Cervical Canal in Normal Indian Adults. Clinical Radiology, 33, 681-685.

https://doi.org/10.1016/s0009-9260(82)80403-0

[9] Lee, H.M., Kim, N.H., Kim, H.J. and Chung, I.H. (1994) Mid-Sagittal Canal Diameter and Vertebral Body/Canal Ratio of the Cervical Spine in Koreans. Yonsei Medical Journal, 35, 446-452. https://doi.org/10.3349/ymj.1994.35.4.446

[10] Taitz, C. (1996) Anatomical Observations of the Developmental and Spondylotic Cervical Spinal Canal in South African Blacks and Whites. Clinical Anatomy, 9, 395-400. https://doi.org/10.1002/(SICI)1098-2353(1996)9:6<395::AID-CA7>3.0.CO;2-A

[11] Gepstein, R., Folman, Y., Sagiv, P., Ben, D.Y. and Halle, T. (1991) Does the Anteroposterior Diameter of the Bony Spinal Canal Reflects Its Size? An Anatomical Study. Surgical and Radiologic Anatomy, 13, 289-291. https://doi.org/10.1007/BF01627760

[12] Sasaki, T., Kadoya, S. and Iizuka, H. (1998) Roentgenological Study of Sagittal Diameter of the Cervical Spinal Canal in Normal Adult Japanese. Neurologia MedicoChirurgica, 38, 83-88. https://doi.org/10.2176/nmc.38.83

[13] Evangelopoulos, D.S., Kontovazenitis, P., Kouris, S., Zlatidou, X., Benneker, L.M., Vlamis, J.A., Korres, D. and Efstathopoulos, N. (2012) Computerized Tomographic Morphometric Analysis of the Cervical Spine. The Open Orthopaedics Journal, 6, 250-254. https://doi.org/10.2174/1874325001206010250

[14] Ulbrich, E.J., Schraner, C., Boesch, C., Hodler, J., Busato, A., Anderson, S.E., Eigenheer, S., Zimmermann, H. and Sturzenegger, M. (2014) Normative MR Cervical Spinal Canal Dimensions. Radiology, 271, 172-182. https://doi.org/10.1148/radiol.13120370

[15] Song, K.J., Choi, B.W., Kim, S.J., Kim, G.H., Kim, Y.S. and Song, J.H. (2009) The Relationship between Spinal Stenosis and Neurological Outcome in Traumatic Cervical Spine Injury: An Analysis using Pavlov's Ratio, Spinal Cord Area and Spinal Canal Area. Clinics in Orthopedic Surgery, 1, 11-18.

https://doi.org/10.4055/cios.2009.1.1.11

[16] Chazono, M., Tanaka, T., Kumagae, Y., Sai, T. and Marumo, K. (2012) Ethnic Differences in Pedicle and Bony Spinal Canal Dimensions Calculated from Computed Tomography of the Cervical Spine: A Review of the English-Language Literature. European Spine Journal, 21, 1451-1458. https://doi.org/10.1007/s00586-012-2295-y

[17] Prasad, S.S., O’Malley, M., Caplan, M., Shackleford, I.M. and Pydisetty, R.K. (2003) MRI Measurements of the Cervical Spine and Their Correlation to Pavlov's Ratio. Spine, 28, 1263-1268. https://doi.org/10.1097/01.BRS.0000065570.20888.AA

[18] Yanase, M., Matsuyama, Y., Hirose, K., et al. (2006) Measurement of the Cervical Spinal Cord Volume on MRI. Journal of Spinal Disorders \& Techniques, 19, 125 129. https://doi.org/10.1097/01.bsd.0000181294.67212.79

[19] Torg, J.S., Naranja, R.J., Pavlov, H., Galinat, B.J., Warren, R. and Stine, R.A. (1996) The Relationship of Developmental Narrowing of the Cervical Spinal Canal to Reversible and Irreversible Injury of the Cervical Spinal Cord in Football Players. The Journal of Bone and Joint Surgery, 78, 1308-1314. https://doi.org/10.2106/00004623-199609000-00003

[20] Morishita, Y., Naito, M. and Wang, J.C. (2011) Cervical Spinal Canal Stenosis: The Differences between Stenosis at the Lower Cervical and Multiple Segment Levels. 
International Orthopaedics, 35, 1517-1522.

https://doi.org/10.1007/s00264-010-1169-3

[21] Miyanji, F., Furlan, J.C., Aarabi, B., Arnold, P.M. and Fehlings, M.G. (2007) Acute Cervical Traumatic Spinal Cord Injury: MR Imaging Findings Correlated with Neurologic Outcome-Prospective Study with 100 Consecutive Patients. Radiology, 243, 820-827. https://doi.org/10.1148/radiol.2433060583

\section{Scientific Research Publishing}

Submit or recommend next manuscript to SCIRP and we will provide best service for you:

Accepting pre-submission inquiries through Email, Facebook, LinkedIn, Twitter, etc. A wide selection of journals (inclusive of 9 subjects, more than 200 journals)

Providing 24-hour high-quality service

User-friendly online submission system

Fair and swift peer-review system

Efficient typesetting and proofreading procedure

Display of the result of downloads and visits, as well as the number of cited articles Maximum dissemination of your research work

Submit your manuscript at: http://papersubmission.scirp.org/

Or contact ojrad@scirp.org 